\title{
L-band Polarimetric Interferometry in Boreal Forest Parameter Estimation, a Case Study
}

\author{
Jaan Praks, Martti Hallikainen \\ Laboratory of Space Technology \\ Helsinki University of Technology \\ Finland \\ Jaan.Praks@tkk.fi
}

\begin{abstract}
In this study we concentrate on the application and validation of forest height estimation by polarimetric SAR interferometry for boreal forest. The study material was collected during the FinnSAR campaign, carried out in Finland in Fall 2003. The main instruments of the campaign were E-SAR airborne radar ( $L$ - and $X$-band) and HUTSCAT helicopter-borne profiling scatterometer ( $\mathrm{X}$ - and $\mathrm{C}$-band). The validated forest height estimation algorithm is based on Random Volume over Ground (RVoG) model inversion by using POLinSAR data. We compare POLinSAR-derived forest height with results from profiling HUTSCAT scatterometer measurements and with ground measurements and discuss the results. Our results show that the forest height values, estimated by means of two different instruments, are in good agreement.
\end{abstract}

Keywords-component; boreal forest; forest height; synthetic aperture radar; polarimetric interferometry; random volume over ground model; scatterometer;

\section{INTRODUCTION}

Along with the launch of the new space-borne SAR sensor generation in 2006-2007 great interest has been taken in coherent image processing techniques. One of the promising new technologies for forest mapping and monitoring is forest height estimation by model based inversion of polarimetric interferometric synthetic aperture radar (POLinSAR) data [1-2]. The model performance has been validated for a large variety of forests, including tropical rainforest [3] and broad-leaved forests [4].

In our study we evaluate how the POLinSAR approach performs for mixed boreal forest in rough terrain. For that we have conducted a case study in southern Finland. The measurements were conducted in the end of September and the beginning of October 2003. The POLinSAR data were collected by DLR's E-SAR airborne radar. Five repeat pass interferometric baselines were measured in a quad-pol mode in L-band together with a single-pass single-pol (VV) Xband interferometric acquisition for DEM generation. The data acquisition covered approximately a $3 \mathrm{~km}$ x $15 \mathrm{~km}$ forested area. Additionally, $11 \mathrm{C}$ - and X-band scattering profiles of the test site forest were measured with the helicopter-mounted HUTSCAT profiling scatterometer [5-6]. Also ground measurements were performed during the campaign and a large database of supporting material was put together.

\author{
Florian Kugler, Konstantinos Papathanassiou, Irena \\ Hajnsek \\ Microwaves and Radar Institute \\ Deutsches Zentrum für Luft- und Raumfahrt \\ Germany
}

This paper is structured as follows. First we describe the test site, measurement campaign and collected datasets, then we show how forest height was calculated from different measurements and how the measurements were cross validated. Finally we discuss the results and present our conclusions.

\section{MeAsurement CAMPaign}

\section{A. $\quad$ Test site}

The test site is located in southern Finland (N $60^{\circ} 11^{\prime}$, E $\left.24^{\circ} 29^{\prime}\right)$, near Helsinki. The area represents typical agricultural land use for southern Finland, where agricultural fields alternate with forest patches and lakes. The forest in the test area is very heterogeneous and consists of rather small stands. The test area incorporates young stands, old stands, mixed stands, clear-cuts, and mires. The main tree species are Scotch pine, spruce, birch and alder. According to a forest inventory, covering part of the study site, the median stand size in the area is $\sim 1$ ha, median age 46 years, median stand mean height $6.3 \mathrm{~m}$, highest stand mean height is $22 \mathrm{~m}$, median stem volume of a stand is $\sim 160 \mathrm{~m}^{3} / \mathrm{h}$. Elevation varies from $15 \mathrm{~m}-80 \mathrm{~m}$ over sea level. The terrain is relatively rough and rocky, especially in forest, because most flat areas are used for agriculture. Rapid elevation changes and rough surface makes the site very challenging for POLinSAR methods. During the campaign deciduous forest was still in full leaf, but discoloration had already begun for broad-leaved species; the scattering properties of tree crowns were presumably very close to summer conditions.

\section{B. E-SAR flight}

The E-SAR flight took place on 29 September 2003 between eight and nine o'clock in the morning. The instrument flew along five parallel tracks, with a baseline of $5 \mathrm{~m}$, and collected quad-pol images in L-band and a single track in a single-pass single-channel (VV) interferometric mode in X-band. The temporal baseline between the two subsequent tracks was approximately 12 - 14 minutes.

Weather during the image acquisition was, according to our weather station in the area, mostly calm, average wind from WSW 0 to $1 \mathrm{~m} / \mathrm{s}$; the highest wind speed reading between 8:00 and 9:00 o'clock was $1.8 \mathrm{~m} / \mathrm{s}$. The wind was measured at $2 \mathrm{~m}$ altitude from ground in the field. 




Figure 1. Forest height map, generated by using L-band POLinSAR, combined with ancillary data. Slant range geometry. Top - near range, bottom - far range. Dotted lines are the HUTSCAT measurement tracks identified by numbers. Solid lines show available forest stand map. Circles denote ground sample plots

\section{HUTSCAT flight}

Reference tree height data were collected by the helicopterborne HUTSCAT scatterometer [5]. The scatterometer is able to collect a vertical backscattering profile along the flight track at $\mathrm{C}$ - and $\mathrm{X}$-band. Our measurement plan was hampered by thick fog and, therefore, the HUTSCAT measurement was carried out on 1 October 2003.

The incidence angle was 0 degrees (vertical), the helicopter location was measured by differential GPS (the attitude was not measured). HUTSCAT measured 11 transects, altogether $36 \mathrm{~km}$. Most of the measurements are concentrated on a $2 \times 2 \mathrm{~km}$ area, covering well the E-SAR near and mid range.

\section{Ground meassurements and supplementary material}

Ground truth data were collected during the E-SAR flight day and on the HUTSCAT flight day. The test plots were located along the HUTSCAT flight lines. Soil moisture and temperature, leaf area index (with LAI2000) were measured and digital photographs were taken. Reference measurements of single tree and stand height were carried out later. Weather information was collected by two portable weather stations. Forest inventory data were made available by the local forest authority for 77 stands, covering a 136-ha area. The forest stand information was gathered in April 2001 and, unfortunately, it may not be sufficiently up to date in some rapidly developing areas. Aerial image mosaic and maps were obtained for the whole test site.

\section{METHODS}

\section{A. $\quad E-S A R$}

The estimation of forest height from interferometric coherence measurements is based on the inversion of the Random Volume over Ground (RVoG) scattering model. Accordingly, the vegetation layer (canopy + branches + trunks) is modelled with a homogeneous layer of given height (corresponding to a mean forest height $h_{V}$ ) located over an impenetrable ground that accounts for any scattering contribution with the phase centre located on the ground. For a given non-zero spatial baseline the volume decorrelation contribution of the interferometric coherence is given by

$$
\tilde{\gamma}_{V}=\exp \left(i \kappa_{z} z_{0}\right) \frac{\tilde{\gamma}_{V 0}+m}{1+m}
$$

where $\varphi_{0}=\kappa_{z} z_{0}$ is the phase related to the ground topography $z_{0}$ and $m$ is the effective ground-to-volume amplitude ratio accounting for the attenuation through the volume:

$$
m=\frac{m_{G}}{m_{V} I_{0}}
$$

$m_{V}$ and $m_{G}$ are ground and volume scattering amplitudes, $\sigma$ is the mean extinction coefficient and $\tilde{\gamma}_{V 0}$ is the volumeonly coherence i.e. the volume decorrelation caused in the absence of the ground layer [1,2]. Neglecting temporal decorrelation and after calibration/compensation of the system and geometry induced decorrelation contributions Eq. 1 can be inverted in terms of a Quad-pol single baseline acquisition [1-2]. For the inversion of Eq. 1 a single-baseline quad-pol L-band (10m nominal spatial baseline) acquisition has been used. Forest mask was generated together with height map. In addition, we also inverted Eq. 1 using the single-pass single-pol X-band acquisition as proposed in [7].

\section{B. HUTSCAT}

The HUTSCAT measured vertical scattering profile data were connected to GPS measurements by using the time stamp. An automatic algorithm was developed to detect the ground peak and the scattering minimum corresponding to tree tops. Tree height was determined by difference in ground peak range and tree top range. The HUTSCAT system does not have an ability to measure attitude and, therefore, the helicopter's $\mathrm{X}$ and $\mathrm{Y}$ coordinates were used as an approximation for the antenna beam location on the ground. This can cause a localization error, depending on measurement system attitude. We assume that the beam localization error is in most cases less than $15 \mathrm{~m}$, this was checked by using ortophotos. In order to validate the tree height measurement, the HUTSCAT-derived estimate was checked with ground measurements in a few points. 


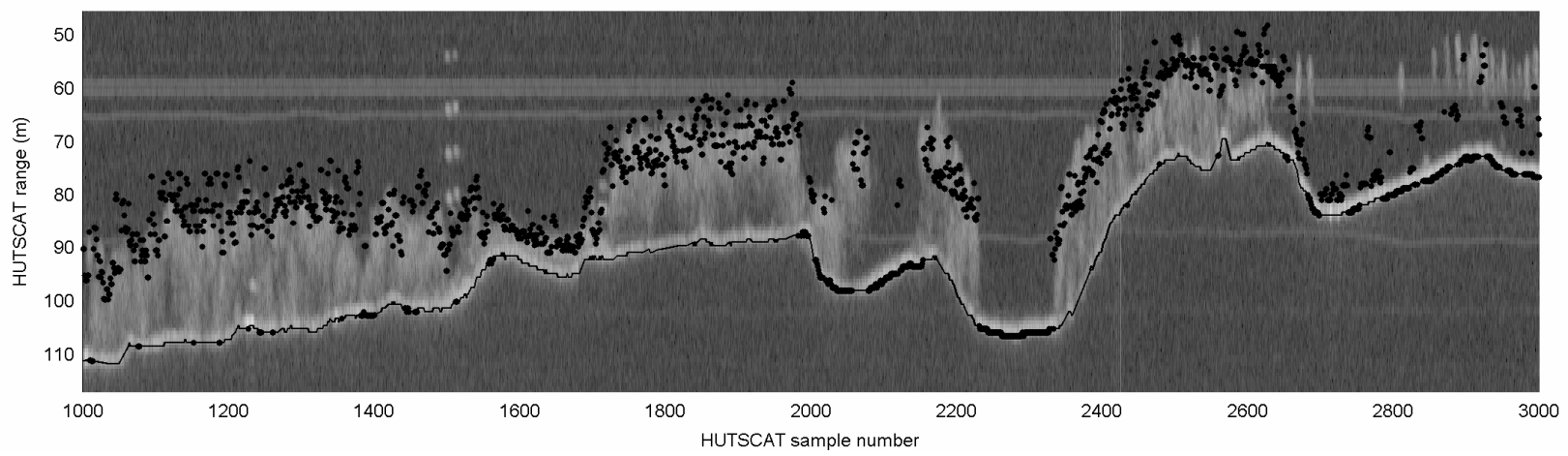

Figure 2. POLinSAR L-band near range forest height estimates on top of HUTSCAT X-band vertical forest backscattering profile, track 1. Black dots represent POLinSAR forest height estimates for L-band $10 \mathrm{~m}$ baseline. On $\mathrm{x}$-axis is HUTSCAT sample number, corresponding to helicopter movement, and on y-axis is HUTSCAT vertical range. White areas correspond to backscattering $(\mathrm{dB})$ from trees and ground. Black line corresponds to automatically detected ground level.



Figure 3. POLinSAR L-band mid-range forest height estimates on top of HUTSCAT X-band vertical forest backscattering profile, track 5. Black dots represent POLinSAR forest height estimates for L-band $10 \mathrm{~m}$ baseline. On $\mathrm{x}$-axis is HUTSCAT sample number, corresponding to helicopter movement, and on y-axis is HUTSCAT vertical range. White areas correspond to backscattering $(\mathrm{dB})$ from trees and ground. Black line corresponds to automatically detected ground level.

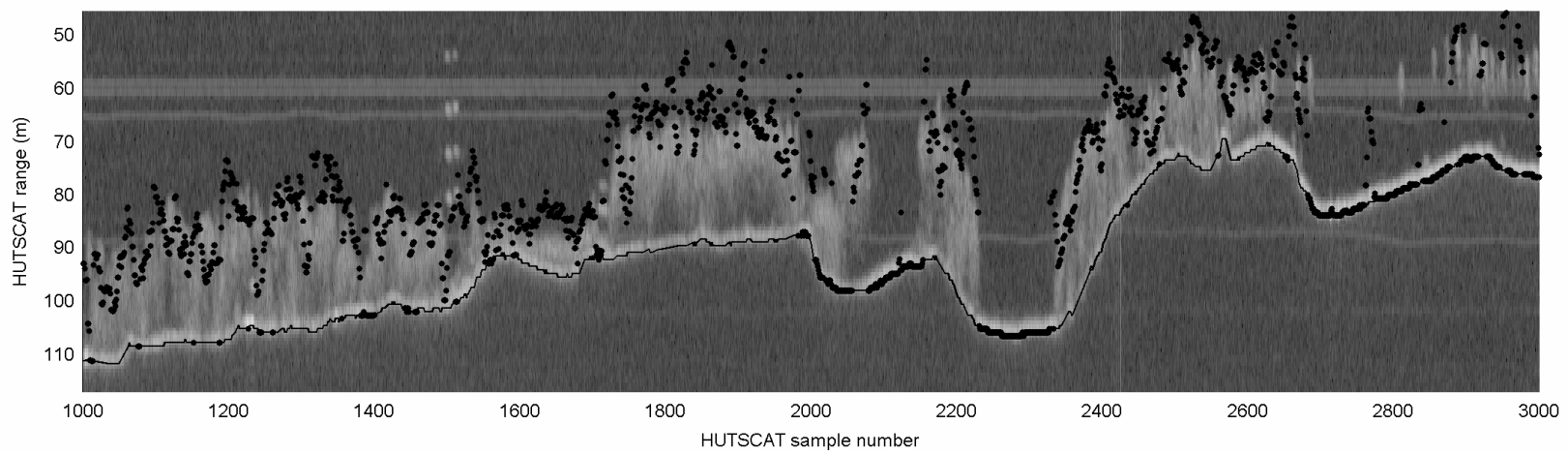

Figure 4. POLinSAR X-band near range forest height estimates on top of HUTSCAT X-band vertical forest backscattering profile, track 1. Black dots represent POLinSAR forest height estimates for X-band $0.8 \mathrm{~m}$ baseline. On $\mathrm{x}$-axis is HUTSCAT sample number, corresponding to helicopter movement, and on y-axis is HUTSCAT vertical range. White areas correspond to backscattering $(\mathrm{dB})$ from trees and ground. Black line corresponds to automatically detected ground level.

The HUTSCAT measurement provided $\sim 32000$ measurements along 11 transects, comprising 24000 height estimates calculated separately for X-and C-band.

\section{Comparison of treeheight measurements}

To validate POLinSAR-derived forest height estimates, we compared them to HUTSCAT measurements and forest inventory data. For this all ancillary data have been converted to the slant range geometry of L-band by using azimuth and range conversion maps, produced during SAR geocoding. Fig 1 show POLinSAR generated forest height map in slant range geometry combined with HUTSCAT measurement tracks and stand inventory vector map.

In order to compare the SAR and HUTSCAT tree height data, HUTSCAT tree height estimates were converted to SAR slant range coordinates and POLinSAR estimates were converted to HUTSCAT range profile coordinates. The comparison was done in slant range on pixel basis. 
However, the pixel-based comparison approach was found difficult; problems were caused especially by the localization error in HUTSCAT data. The tree height in mixed forest can have very rapid fluctuations with large amplitude and, therefore, localization error may cause large variation. In order to better understand the error sources and scattering process we decided to concentrate the comparison mainly on HUTSCAT backscattering profile coordinates.

\section{RESULTS AND DISCUSSION}

Figs 2-4 show part of the HUTSCAT measurement profile in X-band with the POLinSAR tree height measurements on top of it. On x-axis is HUTSCAT sample number, corresponding to helicopter movement, and on y-axis is HUTSCAT vertical range. Lighter areas correspond to backscattering $(\mathrm{dB})$ from trees and ground. Black line corresponds to automatically detected ground level. Black dots correspond to POLinSAR tree height estimates relative to HUTSCAT detected ground line; therefore zero tree height (open areas) dots appear on HUTSCAT ground line. The results in Fig. 2 indicate that estimates derived from Lband 10-m baseline POLinSAR model inversion are in good agreement with HUTSCAT measurements in the SAR nearrange area. A single measurement is somewhat noisy, but the general trend follows tree top level rather closely. For higher forest, the variability in height estimate is higher and for smaller forest the variability is smaller. It seems that the POLinSAR heights are slightly underestimated (i.e. lower that the highest tree tops), but this is in average compensated. Even for very sparse (open-canopy) forest on the right side of the image, with sparse trees the POLinSAR estimates clearly underestimate the tree heights.

When moving to mid range, Fig 3, the L-band estimate tends to overestimate individual areas. In general, detected tree top level is somewhat higher, and in noisy areas tends to have sometimes unrealistically high peaks due to decorrelation.

Experimental X-band derived tree height estimates are shown in Fig. 4. As mentioned in [7], the technique is still under development and uses rather strong assumptions to make inversion possible. However, as seen in Fig 4, also Xband estimates perform rather well, although there is some overestimation and noise. The X-band follows better the actual tree crown structure and penetrates deeper in gaps between the trees. In very sparse areas it sees the scattering centre higher than L-band.

Tree height estimates were also compared to a stand-wise inventory by calculating an average height estimate for every stand. There was very low correlation between stand mean height measured in forest inventory and estimated by either E-SAR or HUTSCAT. However, much better correlation was found between inventory-measured stem volume and tree height estimated by either E-SAR or HUTSCAT. There can be several reasons for this. We suspect that mean height is just poorly measured. The reason can partly be related also to heterogeneous or small stands, where accurate mean height can be rather difficult to measure. We also have to keep in mind that forest mean height is not exactly the mean of all tree heights, especially for mixed and layered forest. As shown in [8] the HUTSCAT-measured forest parameters can be more accurate than normal forest inventory.

\section{CONCLUSIONS}

In this study we have shown that tree height estimation by using L-band interferometric polarimetry and inversion of the Random Volume over Ground model works well for boreal forest. Independent tree height measurements made with the HUTSCAT instrument agree well with POLinSARderived height. We also think that X-band inversion for tree height has a potential at low density forest ecosystems.

Additionally, we have shown that a profiling scatterometer instrument, like HUTSCAT, can give valuable information to support validation of POLinSAR methods and helps to better understand scattering processes in vertically distributed media like forests. Material collected for the study is extensive and gives many possibilities for further studies.

\section{ACKNOWLEDGMENT}

The authors would like to thank the DLR E-SAR team for flexible data processing and the TKK HUTSCAT and ground team for data collection.

\section{REFERENCES}

[1] K.P. Papathanassiou and S.R. Cloude, "Single baseline Polarimetric SAR Interferometry', IEEE Transactions on Geoscience and Remote Sensing, vol. 39, no. 11, pp. 2352-2363, 2001.

[2] S.R. Cloude and K.P., Papathanassiou, "Three-stage inversion process for polarimetric SAR interferometry", IEE Proceedings Radar Sonar and Navigation, vol. 150, no. 3, pp. 125-134, 2003.

[3] M. Brandfass, C. Hofmann, J.C. Mura, K.P Papathanassiou, "Polarimetric SAR interferometry as applied to fully polarimetric rain forest data", Geoscience and Remote Sensing Symposium IGARSS '01, 9-13 July 2001, Proceedings, vol. 6, pp. 2575 - 2577, 2001.

[4] T. Mette, K.P Papathanassiou, I Hajnsek, "Biomass estimation from polarimetric SAR interferometry over heterogeneous forest terrain", Geoscience and Remote Sensing Symposium, 2004. IGARSS '04. 2024 Sept. 2004, Proceedings IEEE International, vol. 1, pp. 511 - 514, 2004.

[5] M. Hallikainen, J. Hyyppä, J. Haapanen, T. Tares, P. Ahola, J. Pulliainen, M. Toikka, "A Helicopter-borne eight-channel ranging scatterometer for remote sensing: Part I: System Description", IEEE TGRS, vol. 31, no. 1, January 1993.

[6] J. Hyyppä, M. Hallikainen, "A Helicopter-borne eight-channel ranging scatterometer for remote sensing: Part II: Forest inventory", IEEE TGRS, vol. 31, no. 1, January 1993.

[7] F. Kugler, F. N. Koudogbo, K. Gutjahr, K. P. Papathanassiou, "Frequency effects in Pol-InSAR Forest Height Estimation". Conference proceedings, EUSAR 2006, Dresden, Germany, 2006.

[8] J.Hyyppä, H. Hyyppä, M. Inkinen, M. Engdahl, S. Linko, Y. Zhu, "Accuracy comparison of various remote sensing data sources in the retrieval of forest stand attributes", Elsevier, Forest Ecology and Management, vol. 128, pp. 109-120, 2000. 